\title{
Dental Caries-A Huge Challenge for Public Health
}

ISSN: 2637-7764

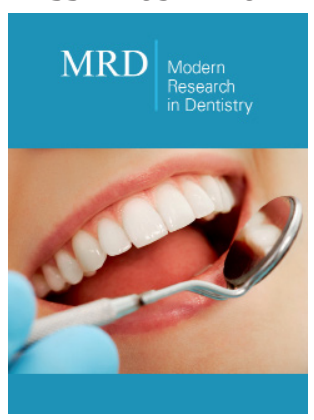

*Corresponding author: Klaudia Suligowska, Department ofDental Technology \& Masticatory Apparatus Disfunctions, Medical University of Gdańsk, Poland

Submission: 嘴 November 18, 2020

Published: 制 December 04, 2020

Volume 5 - Issue 5

How to cite this article: Klaudia Suligowska, Dental Caries-A Huge Challenge for Public Health. Mod Res Dent. 5(5). MRD. 000624. 2020.

DOI: 10.31031/MRD.2020.05.000624

Copyright@ Klaudia Suligowska, This article is distributed under the terms of the Creative Commons Attribution 4.0 International License, which permits unrestricted use and redistribution provided that the original author and source are credited.

\section{Klaudia Suligowska *}

Department of Dental Technology \& Masticatory Apparatus Disfunctions, Medical University of Gdańsk, Poland

\section{Opinion}

The problem of caries disease has become one of the major challenges for public health in countries around the world, while becoming one of the most worrying health phenomena in the world. It is obvious that caries is a pathological process of local nature, leading to decalcification of enamel and dentin, decomposition of hard tooth tissues and, consequently, formation of a cavity, but also a serious risk factor for other diseases. Many studies have shown a significant relationship between periapical tissue inflammation and cardiovascular disease [1-3], diabetes [4,5] and systemic oxidative stress [6].

In the Global Burden of Disease 2015 study, caries in permanent teeth is the most common disease (2.3 billion people) and the 12 th for deciduous teeth (560 million children). It is assumed that the disease accounts for $5-10 \%$ of healthcare budgets in industrialized countries [7]. Due to the significant negative impact of caries on the general health of a person, the dissemination of the phenomenon and its impact on the country's economy, it is extremely important to constantly and intensively implement preventive programs towards caries. In recent years, many recommendations regarding preventive measures for children and adolescents have been published. We will not find in them one best set of actions that should be taken as part of preventive actions, but we will find many identical recommendations in them [8-11]. We can state that preventive measures should be aimed at children and adolescents aged 6 months to 18 years. The recommendations indicate that dental risk assessment should be carried out on the basis of child's age, social / biological factors, protective factors, and clinical findings. Experts also point to the need for health education in the field of proper oral hygiene techniques, nutrition (with a strong emphasis on reducing free sugar), risk factors, the need for follow-up visits and the health consequences of untreated caries. It is also recommended to perform fluoridation, tooth varnishing and sealing in children and adolescents, as well as the use of pastes, gels and rinses at home [8-11].

\section{References}

1. Gomes MS, Hugo FN, Hilgert JB, Sant'Ana Filho M, Padilha DM, et al. (2016) Apical periodontitis and incident cardiovascular events in the Baltimore longitudinal study of ageing. Int Endod J 49(4): 334342 .

2. An GK, Morse DE, Kunin M, Goldberger RS, Psoter WJ (2016) Association of radiographically diagnosed apical periodontitis and cardiovascular disease: a hospital records-based study. J Endod 42(6): 916-920.

3. Messing M, Souza LC, Cavalla F, Kookal KK, Rizzo G, et al. (2019) Investigating potential correlations between endodontic pathology and cardiovascular diseases using epidemiological and genetic approaches. J Endod 45(2): 104-110.

4. Schulze A, Schönauer M, Busse M (2007) Sudden improvement of insulin sensitivity related to an endodontic treatment. J Periodontol 78(12): 2380-2384.

5. Sánchez Domínguez B, López López J, JanéSalas E, Castellanos Cosano L, Velasco Ortega E, et al. (2015) Glycated hemoglobin levels and prevalence of apical periodontitis in type 2 diabetic patients. J Endod 41(5): 601-606 
6. Inchingolo F, Marrelli M, Annibali S, Cristalli MP, Dipalma G, et al. (2013) Influence of endodontic treatment on systemic oxidative stress. Int J Med Sci 11(1): 1-6.

7. WHO (2017) Sugars and dental caries. Genava, Switzerland.

8. American Academy of Pediatric Dentistry (2019) Periodicity of examination. Caries-risk Assessment and Management for Infants, Children, and Adolescents.
9. American Academy of Pediatric Dentistry (2018) Periodicity of examination, Preventive dental services, anticipatory guidance/counseling and oral treatment for infants, children and adolescents. The Reference Manual of Pediatric Dentistry pp. 209-219.

10. American Academy of Pediatric Dentistry (2018) Fluoride therapy. Reference Manual 40(06): 250-253.

11. Mullane DMO, Baez RJ, Jones S, Lennon MA, Petersen PE, et al. (2016) Fluoride and oral health. Community Dental Health 33(2): 69-99. 